ISSN 2072-6651

www.mdpi.com/journal/toxins

Article

\title{
First Report of Ciguatoxins in Two Starfish Species: Ophidiaster ophidianus and Marthasterias glacialis
}

\section{Marisa Silva ${ }^{1,2, \dagger}$, Inés Rodriguez ${ }^{3, \dagger}$, Aldo Barreiro ${ }^{1,2}$, Manfred Kaufmann ${ }^{2,4,5}$, Ana Isabel Neto ${ }^{2,6}$, Meryem Hassouani ${ }^{7}$, Brahim Sabour ${ }^{7}$, Amparo Alfonso ${ }^{3}$, Luis M. Botana ${ }^{3}$ and}

Vitor Vasconcelos ${ }^{1,2, *}$

1 Department of Biology, Faculty of Sciences, University of Porto, Rua do Campo Alegre, Porto 4619-007, Portugal; E-Mails: marisasilva17@gmail.com (M.S.);

aldo.barreiro@gmail.com (A.B.)

2 Interdisciplinary Center of Marine and Environmental Research-CIMAR/CIIMAR, University of Porto, Rua dos Bragas, 289, Porto 4050-123, Portugal;

E-Mails: mkaufmann@ciimar.up.pt (M.K.); aneto@uac.pt (A.I.N.)

3 Department of Pharmacology, Faculty of Veterinary, University of Santiago of Compostela, Lugo 27002, Spain; E-Mails: ines.rodriguez.filgueiras@usc.es (I.R.); amparo.alfonso@usc.es (A.A.); Luis.Botana@usc.es (L.M.B.)

4 Centre of Life Sciences, University of Madeira, Marine Biology Station of Funchal, Funchal 9000-107, Portugal

5 Center of Interdisciplinary Marine and Environmental Research of Madeira - CIIMAR-Madeira, Edif. Madeira Tecnopolo, Caminho da Penteada, Funchal 9020-105, Portugal

6 Department of Marine Biology, University of Azores, Ponta Delgada 9501-801, Portugal

7 Phycology Research Unit-Biotechnology, Ecosystems Ecology and Valorization Laboratory. Faculty of Sciences El Jadida, University Chouaib Doukkali, El Jadida BP20, Morocco; E-Mails: hassouani@hotmail.com (M.H.); sabour.b@ucd.ac.ma (B.S.)

$\dagger$ These authors contributed equally to this work.

* Author to whom correspondence should be addressed; E-Mail: vmvascon@fc.up.pt; Tel.: +351-223-401-814; Fax: +351-223-390-608.

Academic Editor: Michio Murata

Received: 24 July 2015 / Accepted: 16 September 2015 / Published: 21 September 2015

Abstract: Ciguatera fish poisoning (CFP) is a syndrome caused by the ingestion of fish contaminated with Ciguatoxins (CTXs). These phycotoxins are produced mainly by 
dinoflagellates that belong to the genus Gambierdiscus that are transformed in more toxic forms in predatory fish guts, and are more present in the Indo-Pacific and Caribbean areas. It is estimated that CFP causes per year more than 10,000 intoxications worldwide. With the rise of water temperature and anthropogenic intervention, it is important to study the prevalence of CFP in more temperate waters. Through inter- and subtidal sampling, 22 species of organisms were collected, in Madeira and Azores archipelagos and in the northwestern Moroccan coast, during September of 2012 and June and July of 2013. A total of 94 samples of 22 different species of bivalves, gastropods, echinoderms and crustaceans where analyzed by Ultra Performance Liquid Chromatography-Mass Spectometry-Ion Trap-Time of Flight (UPLC-MS-IT-TOF) and Ultra Performance Chromatography- Mass Spectrometry (UPLC-MS). Our main aim was to detect new vectors and ascertain if there were some geographical differences. We detected for the first time putative CTXs in echinoderms, in two starfish species_-M. glacialis and $O$. ophidianus. We detected differences regarding uptake values by organisms and geographical location. Toxin amounts were significant, showing the importance and the need for continuity of these studies to gain more knowledge about the prevalence of these toxins, in order to better access human health risk. In addition, we suggest monitoring of these toxins should be extended to other vectors, starfish being a good alternative for protecting and accessing human health risk.

Keywords: ciguatera; new vectors; Madeira Island; São Miguel Island; Morocco

\section{Introduction}

Ciguatoxins (CTXs) are lipophilic compounds that result from the biotransformation in finfish of precursor gambiertoxins produced by dinoflagellates from the genus Gambierdiscus [1-3]. Geographically, CTXs are typical for the tropical and sub-tropical regions of the Atlantic (C-CTX), Indian (I-CTX) and Pacific (P-CTX) Oceans [1,4-8]. Both the structure and potency of CTXs appear to be geographically determined, in resemblance to Maitoxin that shares the same producer, and to date more than 30 CTX analogues have been described [3-5,7,9-13].

CTXs are polyethers with rigid structure, formed by rings 13-14 fused by ether linkages (Figure 1) [2]. These potent biotoxins are odorless, tasteless, heat resistant and lipid soluble, so they are not destroyed by cooking processes [7]. Regarding action mechanism, CTXs bind to non-selective, non-voltage activated ion channels, causing their opening, leading to the increase of intracellular calcium levels to toxic concentrations [14]. In terms of symptomatology, during the acute period in the first $24 \mathrm{~h}$ gastrointestinal problems such as diarrhea, nausea, abdominal pain and vomiting appear. In addition, cardiovascular complications can occur. Neurologic symptoms that can emerge from within a few hours to two weeks after exposure, like paresthesias, dysesthesias, and hyperesthesias [15].

Ciguatera fish poisoning (CFP) is the most common type of intoxication syndrome, even in non-endemic areas, due to the large quantity of fish exports, and this makes it a worldwide concern [16]. The most common route of intoxication is through ingestion of contaminated fish, being estimated 10,000 to 50,000 intoxications per year [4,17]. Recent reports document the presence of CTXs as far 
north as the Mediterranean [18]. In addition, high abundance of Gambierdiscus cells are not visible as blooms, as in other harmful algal bloom species, and this hinders the process of monitoring and managing of these blooms [19].
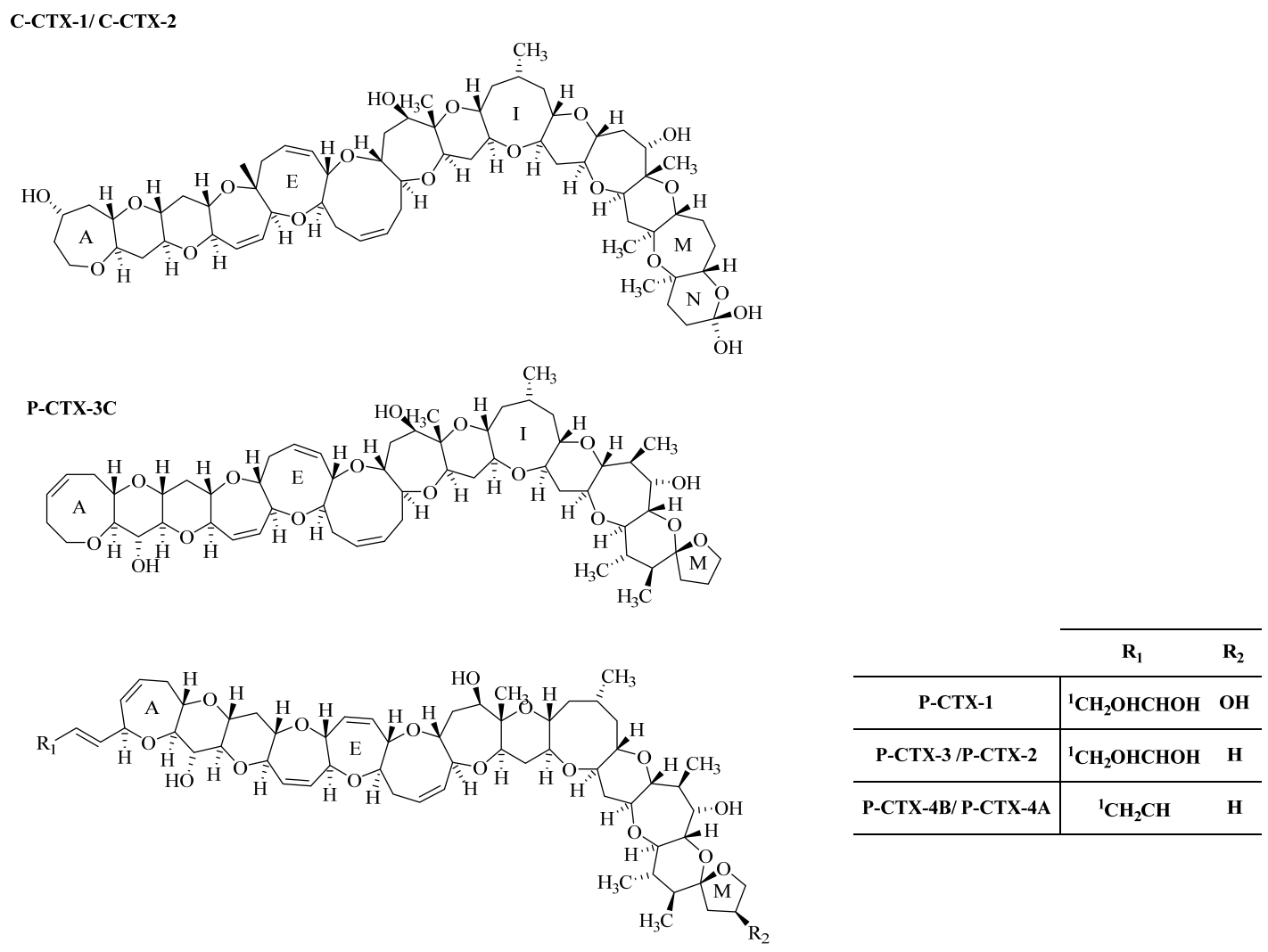

Figure 1. Structures Caribbean (C) and Pacific (P) CTX-group toxin. The epimers, P-CTX-2 (52-epi P-CTX-3), P-CTX-4A (52-epi P-CTX-4B) and C-CTX-2 (56-epi C-CTX-1) are indicated in parenthesis.

The common vectors for these phycotoxins are finfish, some mollusks (e.g., turban snail, Lunella cinerea, and in giant clams, Tridacna gigas), achieving higher concentrations in top predatory fish like groupers (Family: Serranidae), barracuda (Family: Sphyraenidae) and snapper (Family: Lutjanidae) [20]. Regarding the regulatory status in the European Union (EU), EFSA proposes the use of toxicity equivalency factors (TEFs), based on their acute intraperitoneal $\mathrm{LD}_{50}$ in mice, determining eleven values: P-CTX-1 = 1, P-CTX-2 =0.3, P-CTX-3 =0.3, C-CTX-2 $=0.3$, P-CTX-3C $=0.2$, 2,3-dihydroxy PCTX-3C $=0.1,51$-hydroxy P-CTX-3C $=1, \mathrm{P}-\mathrm{CTX}-4 \mathrm{~A}=0.1, \mathrm{C}-\mathrm{CTX}-1=0.1$ and $\mathrm{P}-\mathrm{CTX}-4 \mathrm{~B}=0.05$. In the same scientific opinion on CTXs, EFSA claims that a concentration of $0.01 \mu \mathrm{g}$ P-CTX-1 equivalents $/ \mathrm{kg}$ of fish as expectable not to exert effects in sensitive individuals. In addition, due to very few reported cases for CTX occurrences European markets no limits nor ARfD (acute reference dosage) have been established until now, nor advisement regarding analytical methodologies to use [1]. Nevertheless, Commission Regulation (EC) nr 854/2004stated mandates that checks have to be made to ensure that fishery products containing CTX are forbidden to enter the market [21]. Other countries like the United States of America, have safety levels $(<0.1 \mu \mathrm{g} / \mathrm{kg}$ C-CTX-1 equivalents and $<0.01 \mu \mathrm{g} / \mathrm{kg}$ P-CTX-1 equivalents), other countries opted for more radical measures, like Japan that banned the importation of some fish species reported as CFP vectors (e.g., barracuda) [1,22]. 
The aim of our work was to search for new vectors, to better access the human health risk. We screened the Madeira Island (Madeira archipelago), São Miguel Island (Azores archipelago), and the Moroccan coast by scuba diving expeditions and intertidal harvesting of 22 edible and inedible species. The inedible species were collected due to their importance in the food chain. We hope that our work contributes to the development and establishment of monitoring procedures as well as legislation in the EU to better protect consumers and public health.

\section{Results and Discussion}

In this work, a total of 94 samples were analyzed for CTX plus its analogues from 14 sampling points distributed in three different locations: Madeira Island (Figure 2), São Miguel Island (Figure 3) and along the northwestern Moroccan Coast (Figure 4). Twenty-two species of benthic organisms, including bivalves (mussels), gastropods (sea-snails, sea-slugs and limpets), echinoderms (starfishes, sea-urchins and sea-cucumbers) and crustaceans (barnacles) were collected. The decision to sample these particular species was linked to the fact we wanted to screen edible and commercially important species and inedible species for their importance in the trophic chain. The number of samples collected and average number of specimens needed to set a pooled sample are detailed (Table 1).

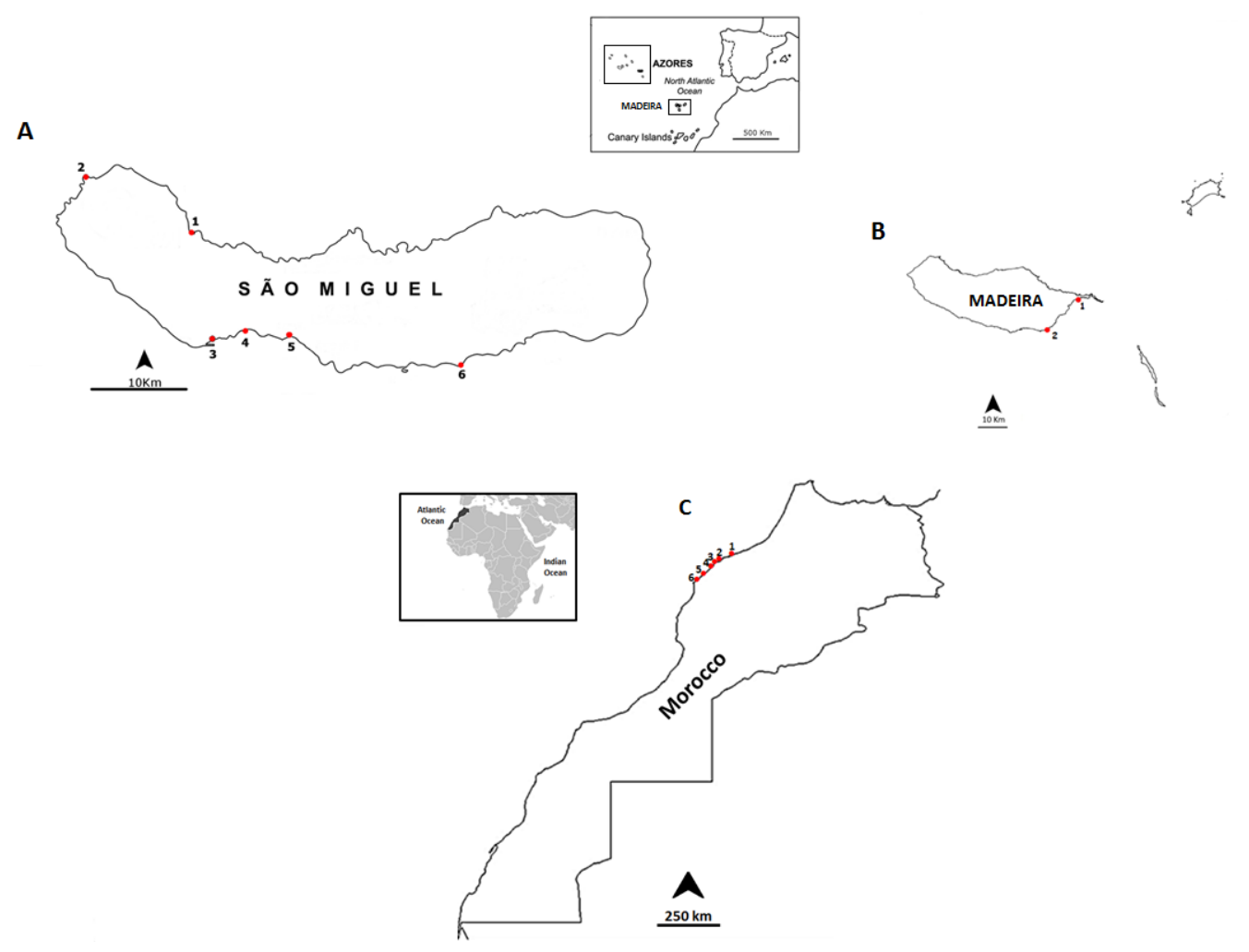

Figure 2. Location of the sampling points: (A) São Miguel island coast, Azores archipelago: 1, Cruzeiro; 2, Mosteiros; 3, Étar; 4, São Roque; 5, Lagoa; and 6, Caloura. (B) Madeira island coast: 1, Reis Magos and 2, Caniçal. (C) Northwestern Moroccan coast: 1, Casablanca Corniche; 2, El Jadida Haras; 3, El Jadida Sâada; 4, Sidi Bouzid; 5, Mrizika; and 6, Oualidia. 
Table 1. Species sampled and their trophic level, average number of specimens comprising a pooled sample (AvNr) and number of samples collected (NrP Samples) on Madeira Island in September 2012, São Miguel Island, Azores, in June 2013 and Morocco in July 2013 and their edibility. Availability of animals is dependent on their geographical distribution and ecology.

\begin{tabular}{|c|c|c|c|c|c|c|}
\hline Species & Trophic Level & Sampling Site(s) & NrP Samples & $\mathrm{AvNr}$ & Edible & Ref. \\
\hline Aplysia depilans & Grazer & Morocco & 3 & 1 & No & {$[23]$} \\
\hline Arbacia lixula & Grazer & Madeira/Azores/Morocco & 9 & 4 & No & {$[24]$} \\
\hline Charonia lampas & 3rd level predator & Madeira/Morocco & 3 & 1 & Yes & [25] \\
\hline Cerithium vulgatum & Grazer & Morocco & 1 & 40 & Yes & [26] \\
\hline Diadema africanum & Grazer & Madeira & 2 & 1 & No & [27] \\
\hline Echinaster sepositus & 2nd level predator & Madeira & 1 & 3 & No & [28] \\
\hline Gibbula umbilicalis & Grazer & Morocco & 3 & 100 & Yes & [29] \\
\hline Holothuria(Platyperona)sanctori & Deposit feeder & Morocco & 4 & 1 & Yes & {$[30,31]$} \\
\hline Marthasterias glacialis & 2nd level predator & Madeira/Azores/Morocco & 8 & 1 & No & {$[32]$} \\
\hline Monodonta lineata & Grazer & Morocco & 5 & 86 & Yes & [29] \\
\hline Mytilus spp. & Filter feeder & Morocco & 4 & 30 & Yes & {$[33]$} \\
\hline Onchidella celtica & Grazer & Morocco & 1 & 50 & No & [34] \\
\hline Ophidiaster ophidianus & Detritivorous & Madeira/Azores & 5 & 1 & No & [28] \\
\hline Pattela aspera & Grazer & Madeira & 2 & 15 & Yes & [32] \\
\hline Patella spp. & Grazer & Morocco & 4 & 12 & Yes & [32] \\
\hline Pattela candei & Grazer & Azores & 3 & 10 & Yes & [32] \\
\hline Paracentrotus lividus & Grazer & Madeira/Azores/Morocco & 7 & 1 & Yes & [35] \\
\hline Pollicipes pollicipes & Filter feeder & Morocco & 3 & 35 & Yes & [32] \\
\hline Sphaerechinus granularis & Grazer & Azores & 4 & 1 & Yes & {$[36]$} \\
\hline Umbraculum umbraculum & Grazer & Madeira & 1 & 1 & No & {$[37]$} \\
\hline Stramonita haemostoma & 2nd level predator & Madeira/Azores/Morocco & 5 & 15 & No & {$[38]$} \\
\hline
\end{tabular}

After sample extraction, the CTXs profile was determined in each sample by Ultra Performance Liquid Chromatography- Mass Spectometry (UPLC-MS) method. Initially, samples were screened by UPLC-MS in Selected Ion Monitoring (SIM) mode for 20 CTXs analogues described in the literature (Table 2) and in seven samples some suspicious peak was detected, all of them from starfish.

Table 2. Screened CTXs UPLC-MS in Positive Mode.

\begin{tabular}{ccl}
\hline Compound Name & Mass & Polarity \\
\hline I-CTX-3 and I-CTX-4 & 1157.6 & Positive \\
Unknown CTX & 1143.6 & Positive \\
Caribean-CTX & 1141.7 & Positive \\
C-CTX-1127 & 1127.6 & Positive \\
CTX-1B & 1111.6 & Positive \\
54-deoxy-CTX-1B & 1095.6 & Positive \\
52-epi-54-deoxy-CTX-1B & 1079.6 & Positive \\
M-CTX-4A and M-CTX-4B & 1061.6 & Positive \\
CTX-4A and CTX-4B & 1060 & Positive \\
MTX small & &
\end{tabular}


Table 2. Cont.

\begin{tabular}{ccc}
\hline Compound Name & Mass & Polarity \\
\hline 2,3-OH-CTX-3C & 1055.6 & Positive \\
M-CTX-3C methylacetal & 1041.6 & Positive \\
2-OH-CTX-3C and M-CTX-3C & 1040.6 & Positive \\
Analogs CTX & 1039.6 & Positive \\
51-OH-CTX-3C & 1023.6 & Positive \\
49-epo-CTX-3C and CTX-3C & 1159.6 & Positive \\
Unknown CTX & & \\
\hline
\end{tabular}

Afterwards, the scan of each sample was carefully analyzed, checking the characteristic mass pattern fragmentation of CTX; that is, the formation of sodium and ammonium adducts and losses of water. In this sense, Figure 3 shows the SIM and the spectrum of CTX-3C standard. The mass spectrum from Figure 3B showed the ion CTX3C $[\mathrm{M}+\mathrm{H}]^{+} \mathrm{m} / z$ 1023.5, and the water losses $m / z 1005.5$ associated with $\left[\mathrm{M}+\mathrm{H}-\mathrm{H}_{2} \mathrm{O}\right]^{+}$and $m / z 987.5$ due to second water lost $\left[\mathrm{M}+\mathrm{H}-2 \mathrm{H}_{2} \mathrm{O}\right]^{+}$. In addition, the sodium adduct $[\mathrm{M}+\mathrm{Na}]^{+} \mathrm{m} / z 1045.7$ is also detected.

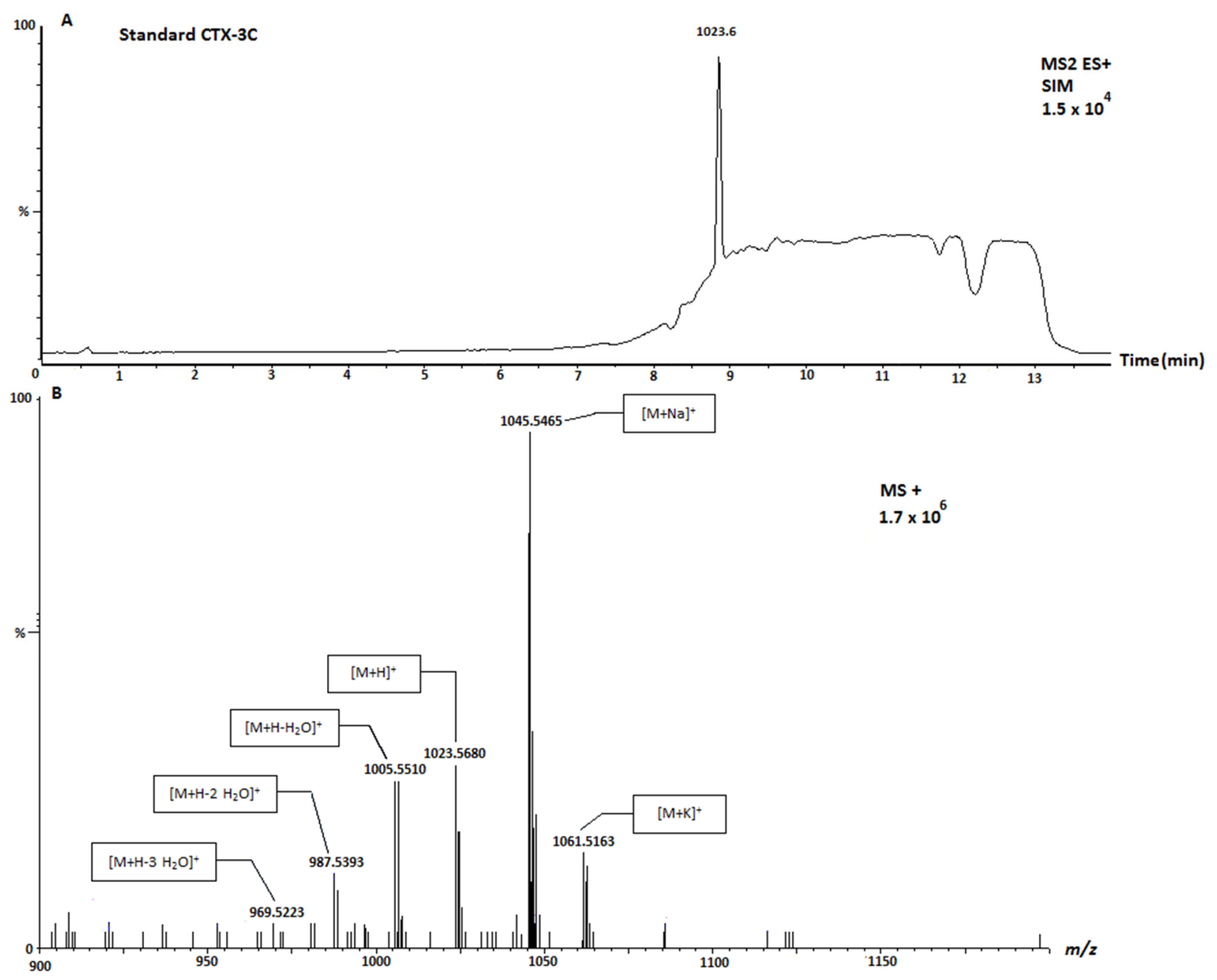

Figure 3. Selected Ion Monitoring (SIM) chromatogram (A) and mass spectrum (B) of standard CTX-3C. SIM obtained by UPLC-MS/MS and spectrum obtained by UPLC-MS-IT-TOF. 
Through this analysis, three CTX analogues were detected. From SIM data of samples, $\mathrm{m} / \mathrm{z} 1111.5$ was found and from scan mass mode $(\mathrm{m} / \mathrm{z}$ 800-1300) of samples, two molecules with $\mathrm{m} / \mathrm{z} 1109.5$ and $\mathrm{m} / \mathrm{z} 1123.5$ were found. The mass spectrum of these molecules (Figure 4) shows the typical fragmentation pattern of CTX-like compounds, with several losses of water and adducts of ammonium and sodium. The mass spectrum in Figure 4A shows two intense masses, one $\left([\mathrm{M}+\mathrm{H}]^{+}\right)$at $\mathrm{m} / z 1111.5$ and other $\left([\mathrm{M}+\mathrm{Na}]^{+}\right)$at $m / z$ 1133.5. Moreover, five losses of water were observed while the ammonium adduct did not appear, probably due to its low intensity. Therefore CTX-1B, $m / z 1111.5$, could be proposed, although not confirmed due to the absence of a standard. The mass spectrum in Figure 4B shows an intense mass $\left(\left[\mathrm{M}+\mathrm{NH}_{4}\right]^{+}\right)$at $m / z 1116.6$ associated with ammonium adduct from $\mathrm{m} / z$ 1109.5. The other three masses shown in the spectrum correspond to one, two and three losses of water at $\mathrm{m} / \mathrm{z} 1099.6$ and 1073.5 and 1055.5, respectively, from $\mathrm{m} / \mathrm{z} 1109.5$ molecule. The mass spectrum in Figure 4C shows an ion at $[\mathrm{M}+\mathrm{H}]^{+} \mathrm{m} / z 1123.5$ and two intense masses, $\left[\mathrm{M}+\mathrm{NH}_{4}\right]^{+}$at $\mathrm{m} / z 1140.5$ and $[\mathrm{M}+\mathrm{Na}]^{+}$at $\mathrm{m} / \mathrm{z}$ 1145.5. In addition, the four losses of water and the potassium adduct of $\mathrm{m} / \mathrm{z} 1123.5$ were also detected in the spectrum.

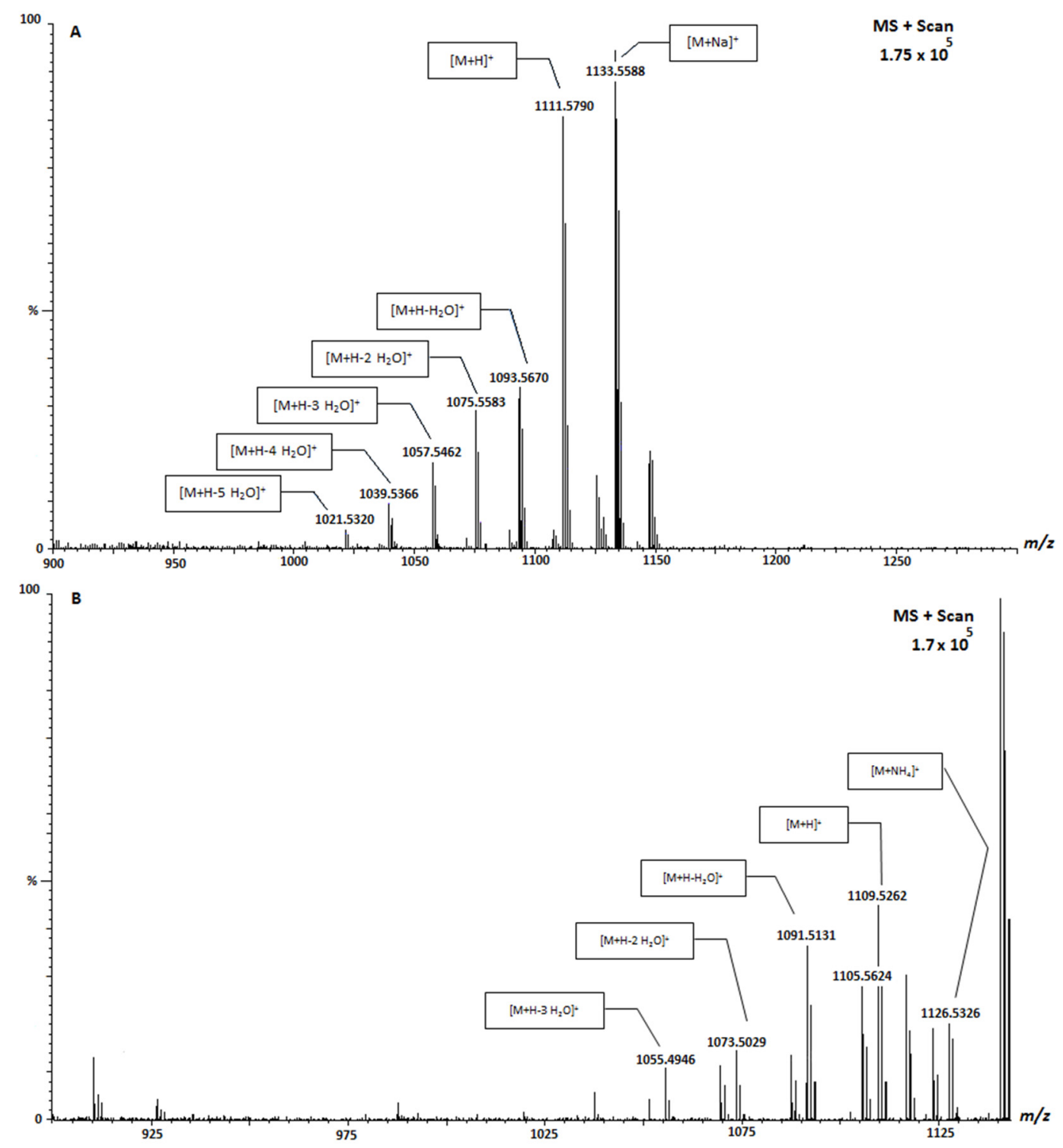

Figure 4. Cont. 


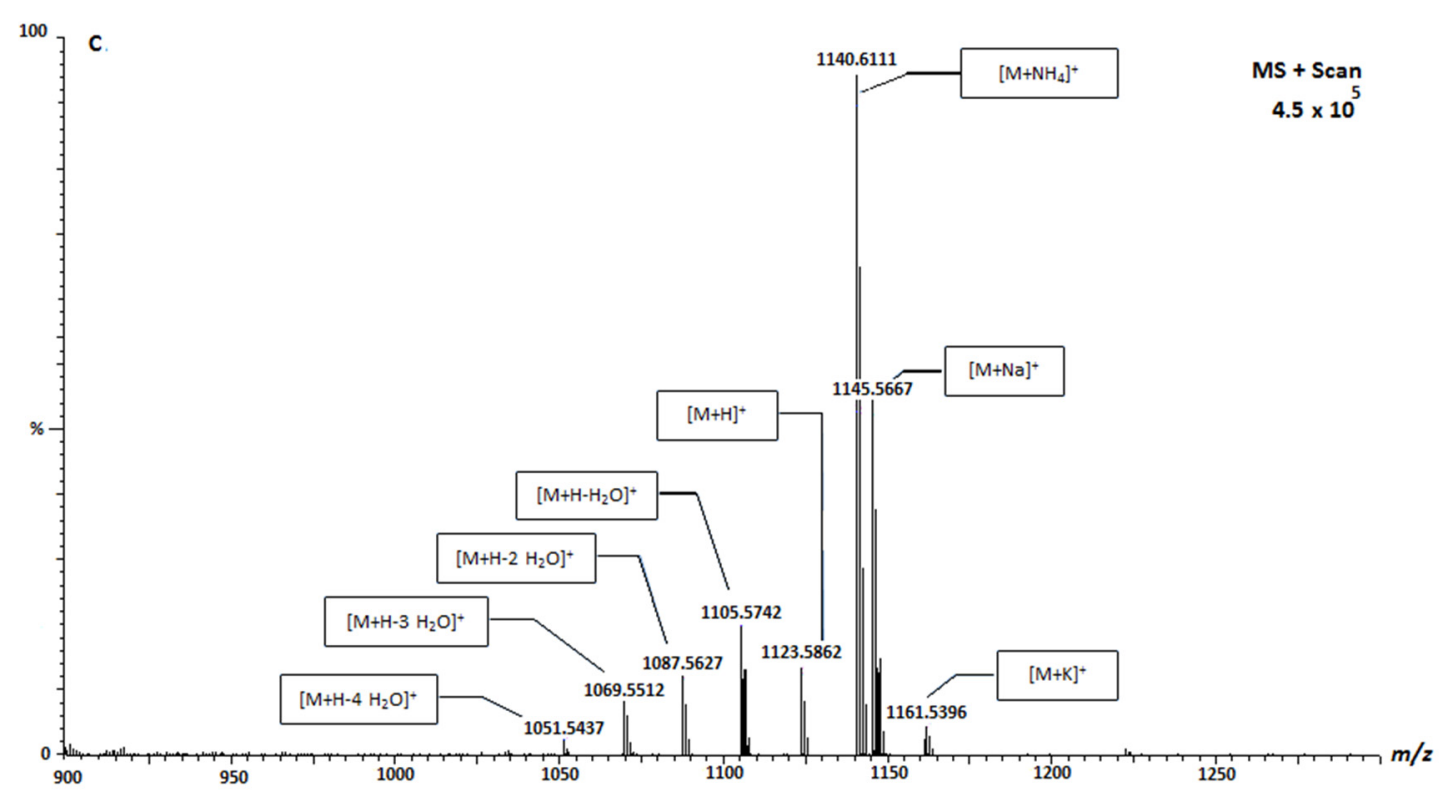

Figure 4. MS2 spectrum of CTX analogue at $m / z$ 1111.5 $[\mathrm{M}+\mathrm{H}]^{+}(\mathbf{A})$; CTX analogue at $m / z 1109.5[\mathrm{M}+\mathrm{H}]^{+}(\mathbf{B})$; and CTX analogue $m / z$ 1123.5 $[\mathrm{M}+\mathrm{H}]^{+}(\mathbf{C})$. Spectra obtained by Ultra Performance Liquid Chromatography-Mass Spectometry-Ion Trap-Time of Flight UPLC-MS-IT-TOF.

Once the presence of CTX analogues was identified, the toxin amount was quantified (Table 3). In order to calculate concentrations of CTX analogues, it was assumed that related analogues would give a similar response to that of CTX-3C, because of this, and since there is an absence of correspondence with EFSAs, TEFs results will be expressed in $\mu \mathrm{g}$ CTX-3C equivalents/Kg. Therefore, the calibration curve was done with CTX-3C standard. The quantification of these toxins was carried out using SIM acquisition in positive mode. For CTX-3C standard, a good seven-point calibration curve with range between $18.75-600 \mathrm{ng} / \mathrm{mL}$ was obtained $(\mathrm{R} 2=0.999)$. The limit of detection (LOD) was $1.125 \mu \mathrm{g} / \mathrm{Kg}$ and the limit of quantification (LOQ) was $3.75 \mu \mathrm{g} / \mathrm{Kg}$.

Table 3. Presumed CTX detected in UPLC-MS (FW-Fresh weight).

\begin{tabular}{cccccc}
\hline Sample & Location & Species & $\begin{array}{c}\text { 1111 }(\boldsymbol{\mu g} \text { CTX-3C } \\
\text { Equivalents/KgFw) }\end{array}$ & $\begin{array}{c}\mathbf{1 1 2 3}(\boldsymbol{\mu g} \text { CTX-3C } \\
\text { Equivalents/KgFw) }\end{array}$ & $\begin{array}{c}1109(\boldsymbol{\mu g} \text { CTX-3C } \\
\text { Equivalents/KgFw })\end{array}$ \\
\hline $341 \# 1$ & Madeira & O. ophidianus & 21.55 & 7.24 & \\
$341 \# 2$ & Madeira & O. ophidianus & 46.49 & 29.80 & \\
$411 \# 2$ & Azores & M. glacialis & $<\mathrm{LOQ}$ & $<\mathrm{LOQ}$ & \\
412 & Azores & O. ophidianus & 19.73 & & \\
424 & Azores & O. ophidianus & 124.04 & 30.90 & \\
$426 \# 1$ & Azores & M. glacialis & 7.92 & & 4.40 \\
435 & Azores & O. ophidianus & 58.78 & & \\
\hline
\end{tabular}

Only $7.45 \%$ of the 94 samples analyzed were quantifiable for CTX. All of the measurable samples were one of two starfish species, O. ophidianus and M. glacialis, from Portuguese territory. This is the first report of CTX in echinoderms. Average concentrations detected ranged from $4.40 \mu \mathrm{g} \mathrm{CTX-3C}$ equivalents/Kg fresh weigh (fw), to $124.04 \mu \mathrm{g}$ CTX-3C equivalents/Kg fw in O. ophidianus, if it were 
possible to apply EFSAs, TEFs both would be above the U.S. American safety level $(<0.1 \mu \mathrm{g} / \mathrm{kg}$ C-CTX-1 equivalents and $<0.01 \mu \mathrm{g} / \mathrm{kg}$ P-CTX-1 equivalents) [22]. Regarding statistics, the first step of the gamma hurdle model was a GLZ performed with the data of presence/absence of CTX with Binomial distribution of the error. The results of the model's analysis of deviance are shown in Table 4, as well as the coefficients rescaled to a logistic probability $(0,1)$. Sampling site had no significant effect. Among sampling sites, the coefficients showed the lowest probability of occurrence in Morocco, and the highest in Madeira. The second part of the model, which considers the variation in CTX concentration, analyzed with a Gamma distribution of the error among those samples showing positive results, did not show significance of sampling site as factor either, although its $p$ value was closer to significance (Table 4). Looking at model coefficients, it is clear that the largest concentrations found occurred in Azores Islands, and lowest in Morocco (zero). This differs from the probability results of the presence/absence data.

The analysis performed with starfish species as factor (Table 5) showed significant differences in both the presence/absence and the analysis of the positives (differences in putative CTX concentrations), conclusively, $O$. ophidianus had both higher probability of showing a positive result, and significantly higher amounts of toxin per body mass. This can be explained by to their distinct feeding habits, since O. ophidianus is a detritivorous acquiring CTX from the sediment bed, against the predatory ones from M. glacialis. In addition, Llewellyn (2010) suggested that the rise of water temperature, derived by climate change, can increase the incidence of CFP in Papua New Guinea from 35-70 per thousand people in 1990 to $160-430$ per thousand people in 2050 [39]. In addition, it is known that the rise of water temperature can influence the growth rate of the producers [40], toxin production as well as the uptake rate of the vectors $[41,42]$, and that could be the main reason of the differences between sampling sites, though Morocco and Madeira are at the same latitude. Nevertheless, the main species that we detected quantifiable amounts of CTX is absent in Morocco. Since Madeira and Azores archipelagos present oligotrophic waters, making these ecosystems poor in bivalves, the red starfish (O. ophidianus) presents a possible alternative as key species for CTX monitoring. We have to interpret the results from our models carefully, since the actual number of data is low. This may affect the non-significance of the models from sampling sites (Table 4) where the differences found might become significant by simply adding more data. However, the models using species as factor (Table 5) reveal a strong pattern that is not affected by the small number of data.

Table 4. Results of the gamma hurdle model for CTX occurrence with sampling site as factor.

\begin{tabular}{ccccc}
\hline \multicolumn{5}{c}{ Analysis of Deviance } \\
\hline Model & Factor & $\boldsymbol{\chi}^{\mathbf{2}}$ & $\boldsymbol{d}$ & $\boldsymbol{p}$ \\
\hline \multirow{2}{*}{ Binomial Error } & Site & 2.9 & 2 & 0.23 \\
& Rescaled model coefficients for Site: Intercept (Azores) $=0.36 ;$ Madeira $=0.78 ;$ Morocco $=4 \times 10^{-8}$ \\
\hline \multirow{2}{*}{ Gamma Error } & Site & 5.5 & 2 & 0.06 \\
& Rescaled model coefficients for Site: Intercept (Azores) $=229 ;$ Madeira $=1.39 ;$ Morocco $=0.004$ \\
\hline
\end{tabular}


Table 5. Results of the gamma hurdle model for CTX occurrence with starfish species as factor.

\begin{tabular}{ccccc}
\hline \multicolumn{5}{c}{ Analysis of Deviance } \\
\hline Model & Factor & $\boldsymbol{\chi}^{\mathbf{2}}$ & $\boldsymbol{d f}$ & $\boldsymbol{p}$ \\
\hline \multirow{2}{*}{ Binomial Error } & Species & 8.5 & 1 & $<0.01$ \\
& Rescaled model coefficients: Intercept $($ M. glacialis $)=0.11 ;$ & O. ophidianus $=0.98$ \\
\hline \multirow{2}{*}{ Gamma Error } & Organism & 9.7 & 1 & $<0.01$ \\
& Rescaled model coefficients: Intercept & (M. glacialis $)=9.4 ;$ O. ophidianus $=57.7$ \\
\hline
\end{tabular}

Our results add new information to this topic, we can say, to the best of our knowledge, that this is the first report of putative CTX in starfish. It is also noteworthy that significant amounts of this group of toxins were detected at the bottom of the trophic chain. We hope this contribute towards the establishment of legislation, as well as the promotion of the monitoring of these toxins in the EU.

\section{Experimental Section}

\subsection{Selected Species and Sampling Sites}

The coasts of the Portuguese islands Madeira (Madeira archipelago), São Miguel (Azores archipelago) and the northwestern coast of Morocco, were surveyed for non-traditional vector species for Ciguatoxins. Several edible and non-edible species were selected $(n=22)$ to search for potential new vectors and also the prevalence of the screened biotoxins in the food web: gastropods (Aplysia depilans, Cerithium vulgatum, Charonia lampas, Gibbula umbilicalis, Monodonta lineata, Onchidella celtica, Patella tenuis tenuis, Patella aspera, Patella candei, Patella spp., Stramonita haemostoma, Umbraculum umbraculum), crustaceans (Pollicipes pollicipes), bivalves (Mytilus spp.), starfish (Echinaster sepositus, Marthasterias glacialis, Ophidiaster ophidianus), sea-cucumber (Holothuria (Platyperona) sanctori), sea-urchins (Arbacia lixula, Diadema africanum, Paracentrotus lividus, Sphaerechinus granularis). Benthic organisms were harvested from intertidal areas during low tide and by scuba diving expeditions: the Madeira Island was surveyed in September 2012, and São Miguel Island, Azores, and the Moroccan coast were sampled in June and July 2013, respectively. Sampling sites are displayed in Table 6.

Two samples of Patella tenuis tenuis and P. aspera were purchased in local markets in Madeira, being caught in the northern coast of the island $\left(32^{\circ} 51^{\prime} 17.02^{\prime \prime} \mathrm{N} ; 17^{\circ} 01^{\prime} 54.02^{\prime \prime} \mathrm{W}\right)$. Organisms were transported to the laboratory in refrigerated containers. Samples were frozen at $-20{ }^{\circ} \mathrm{C}$, if they were not processed immediately. 
Table 6. Sampling Sites and respective geographical coordinates, surveyed during September of 2012 and June and July of 2013.

\begin{tabular}{|c|c|c|c|}
\hline Date & Location & Sampling Site & Geographic Coordinates \\
\hline \multirow{2}{*}{ September 2012} & \multirow{2}{*}{ Madeira Island } & Reis Magos & $32^{\circ} 39^{\prime} 16.21^{\prime \prime} \mathrm{N} ; 16^{\circ} 49^{\prime} 05.29^{\prime \prime} \mathrm{W}$ \\
\hline & & Caniçal & $32^{\circ} 44^{\prime} 20.08^{\prime \prime} \mathrm{N} ; 16^{\circ} 44^{\prime} 17.55^{\prime \prime} \mathrm{W}$ \\
\hline \multirow{6}{*}{ June 2013} & \multirow{6}{*}{ São Miguel Island } & Cruzeiro & $37^{\circ} 50^{\prime} 31.19^{\prime \prime} \mathrm{N} ; 25^{\circ} 41^{\prime} 33.61^{\prime \prime} \mathrm{W}$ \\
\hline & & Étar & $37^{\circ} 44^{\prime} 19.31^{\prime \prime} \mathrm{N} ; 25^{\circ} 39^{\prime} 38.84^{\prime \prime} \mathrm{W}$ \\
\hline & & São Roque & $37^{\circ} 45^{\prime} 15.35^{\prime \prime} \mathrm{N} ; 25^{\circ} 38^{\prime} 31.60^{\prime \prime} \mathrm{W}$ \\
\hline & & Mosteiros & $37^{\circ} 53^{\prime} 25.57^{\prime \prime} \mathrm{N} ; 25^{\circ} 49^{\prime} 14.72^{\prime \prime} \mathrm{W}$ \\
\hline & & Lagoa & $37^{\circ} 44^{\prime} 42.38^{\prime \prime} \mathrm{N} ; 25^{\circ} 19^{\prime} .47^{\prime \prime} \mathrm{W}$ \\
\hline & & Caloura & $37^{\circ} 42^{\prime} 49.34^{\prime \prime} \mathrm{N} ; 25^{\circ} 29^{\prime} 54.54^{\prime \prime} \mathrm{W}$ \\
\hline \multirow{6}{*}{ July 2013} & \multirow{6}{*}{ Morocco Coast } & Casablanca corniche & $33^{\circ} 36^{\prime} 01.2^{\prime \prime} \mathrm{N} ; 7^{\circ} 39^{\prime} 57.5^{\prime \prime} \mathrm{W}$ \\
\hline & & E1 Jadida Haras & $33^{\circ} 14^{\prime} 42.0^{\prime \prime} \mathrm{N} ; 8^{\circ} 28^{\prime} 37.5^{\prime \prime} \mathrm{W}$ \\
\hline & & E1 Jadida Sâada & $33^{\circ} 14^{\prime} 42.4^{\prime \prime} \mathrm{N} ; 8^{\circ} 32^{\prime} 26.9^{\prime \prime} \mathrm{W}$ \\
\hline & & Sidi Bouzid & $33^{\circ} 13^{\prime} 57.1^{\prime \prime} \mathrm{N} ; 8^{\circ} 33^{\prime} 20.9^{\prime \prime} \mathrm{W}$ \\
\hline & & Mrizika & $32^{\circ} 57^{\prime} 21.8^{\prime \prime} \mathrm{N} ; 8^{\circ} 46^{\prime} 53.2^{\prime \prime} \mathrm{W}$ \\
\hline & & Oualidia & $32^{\circ} 43^{\prime} 55.8^{\prime \prime} \mathrm{N} ; 9^{\circ} 02^{\prime} 57.6^{\prime \prime} \mathrm{W}$ \\
\hline
\end{tabular}

\subsection{Reagents}

Acetonitrile and methanol were supplied by Panreac (Barcelona, Spain). All solvents employed in this work were high performance liquid chromatography or analytical grade and the water was distilled and passed through a water purification system (Milli-Q, Millipore, Madrid, Spain). Formic acid was purchased from Merck (Darmstadt, Germany). Ammonium formate was from Fluka (Sigma-Aldrich, Madrid, Spain).

A synthetic standard of CTX-3C was provided by Dr. Masahiro Hirama. The methodology applied for the synthesis was described for the first time in 2001 and improved in 2004 [43,44].

\subsection{Sample Extraction}

The Otero et al. (2010) extraction protocol was followed [45]. The efficiency of the method was studied by analyzing the extracts discarded in each stage of the protocol. Data showed no loss of toxin in each step. The results agree with the efficiency achieved in the method previously described ( $>95 \%$ for P-CTX-1B) [46]. Animals were dissected and homogenized with a blender (A320R1, $700 \mathrm{~W}$, Moulinex, Lisbon, Portugal) in pooled groups in order to obtain $2 \mathrm{~g}$ of tissue, with the exception of Aplysia depilans, Charonia lampas, Diadema africanum, Holothuria (Platyperona) sanctori, Marthasterias glacialis, Ophidiaster ophidianus, Paracentrotus lividus, Sphaerechinus granularis, and Umbraculum umbraculum. In these cases, each animal was treated separately since they had enough extractable biomass. The homogenized tissue was cooked for $20 \mathrm{~min}$ at $70{ }^{\circ} \mathrm{C}$, then homogenized with $8 \mathrm{~mL}$ of Methanol/Hexane (3:1), sonicated (1 min, $70 \mathrm{~Hz}$, Vibra Cell, Sonic \& Materials, Newtown, CT, USA), and subsequently centrifuged at $4000 \mathrm{rpm}$ for $20 \mathrm{~min}$. The upper hexane layer was discarded, and the lower methanol phase was filtered through a $0.45-\mu \mathrm{m}$ filter (Millipore Ultrafree-MC centrifugal filter units, Bedford, MA, USA). The resulting filtered was diluted into methanol water (50:50). Thereafter Solid Phase Extraction (SPE) was performed using $\mathrm{C}_{18}$ SPE cartridges $(500 \mathrm{mg} / 3 \mathrm{~mL}$ volume from Supelco, 
Bellefonte, PA, USA). Cartridges were previously conditioned with $4 \mathrm{~mL}$ of milliQ water, then samples were loaded and washed with 65\% Methanol, and finally samples were eluted in $80 \%$ Methanol. Thereafter, samples were mixed with $4.2 \mathrm{~mL}$ of $1 \mathrm{M} \mathrm{NaCl}$ and $6.7 \mathrm{~mL}$ of Chloroform and centrifuged for $4 \mathrm{~min}$ at $2000 \mathrm{rpm}$ (Centrifugal-Legend RT, Sorvall, Waltham, MA, USA). The upper methanolic layer was discarded and the lower organic layer was evaporated to dryness in a rotary evaporator (Büchi, Flawil, Switzerland) and dissolved in $4 \mathrm{~mL}$ chloroform. For reducing matrix interference, another cleanup procedure was done with Silica Sep-Pak cartridges (Waters, Milford, CT, USA). After loading the sample cartridges were conditioned with chloroform, samples were washed with chloroform and eluted $90 \%$ of chloroform. Extract was concentrated to dryness and then re-suspended in methanol. In Figure 5 is displayed the totality of the purification procedure. Before UPLC-MS analysis, positive samples were confirmed and the exact mass was obtained by UPLC-MS-IT-TOF.

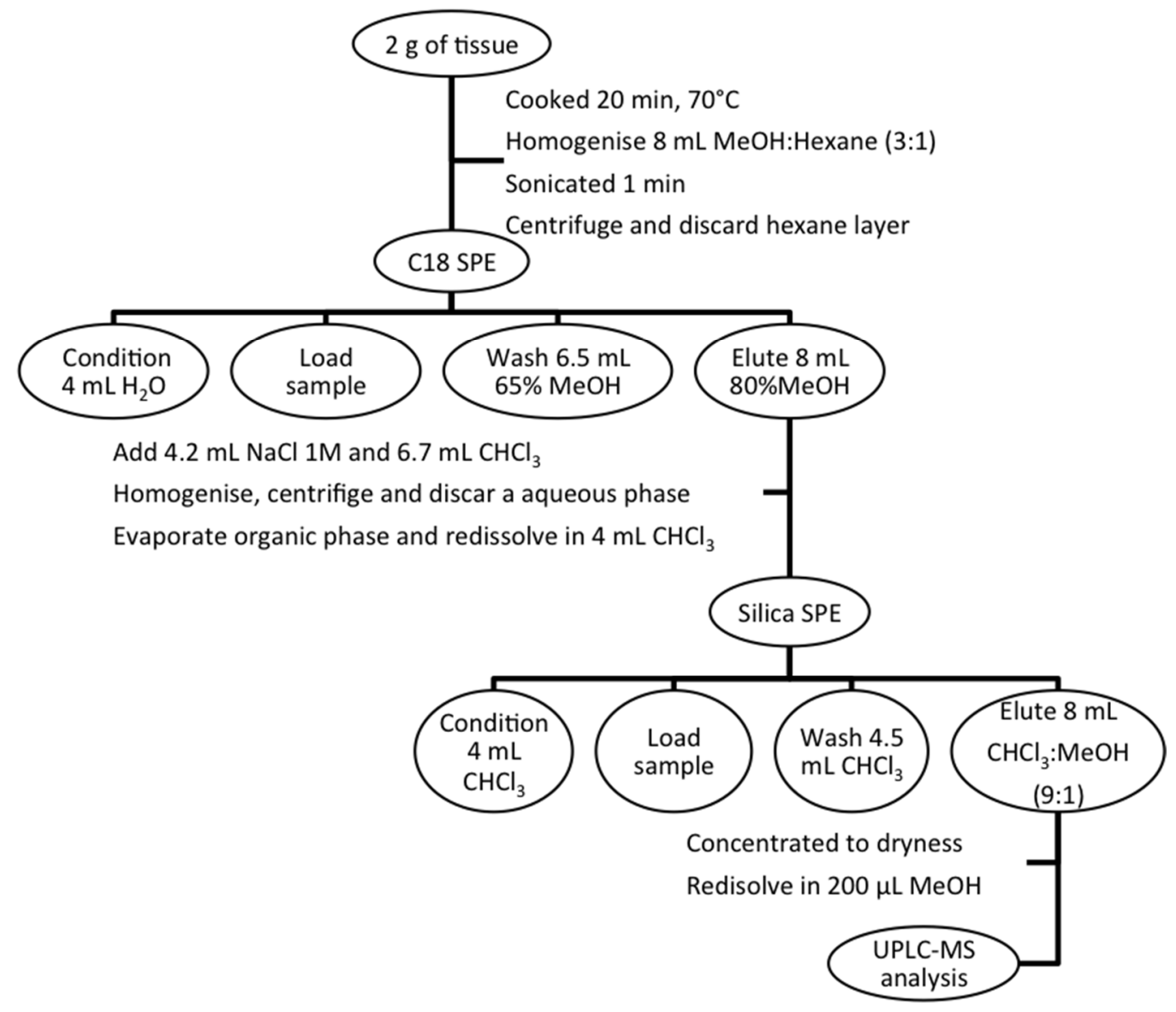

Figure 5. CTX purification scheme.

\subsection{UPLC-MS Conditions}

For the analysis, a 1290 Infinity ultra-high-performance liquid chromatography (UHPLC) system coupled to a 6460 Triple Quadrupole mass spectrometer (both Agilent Technologies, Waldbronn, Germany) was used. Chromatographic separation was performed at $35{ }^{\circ} \mathrm{C}$, the injection volume was $5 \mu \mathrm{L}$ and flow rate of $0.4 \mathrm{~mL} / \mathrm{min}$ using a column AQUITY UPLC BEH C18 $(2.1 \times 100 \mathrm{~mm}, 1.7 \mu \mathrm{m}$, Waters, Manchester, UK). The nitrogen generator is a Nitrocraft NCLC/MS from Air Liquid (Madrid, Spain). Mobile phases A and B were water and acetronitrile:water (95:5), respectively, both acidified 
with $50 \mathrm{mM}$ formic acid and $2 \mathrm{mM}$ ammonium formate. Chromatographic separation was performed by gradient elution starting with $50 \%$ B for $2.5 \mathrm{~min}$, then increasing to $100 \%$ B for $4.5 \mathrm{~min}$., this condition was hold for $4.5 \mathrm{~min}$ and reducing afterward to $50 \% \mathrm{~B}$ over $0.1 \mathrm{~min}$. This proportion was maintained for 2.4 min, until the next injection to equilibrate the system. The electrospray (ESI) source of 6460 mass spectrometer was operated with the following values of source-dependent parameters: gas temperature, $350{ }^{\circ} \mathrm{C}$; gas flow, $8 \mathrm{~L} / \mathrm{min}$; sheath gas temperature, $400{ }^{\circ} \mathrm{C}$; sheath gas flow, $11 \mathrm{~L} / \mathrm{min}$, nebulizer, $45 \mathrm{psi}$; capillary voltage, and $4000 \mathrm{~V}$; and nozzle voltage $0 \mathrm{~V}$. All analyses were performed in MS scan and selected ion monitoring (SIM).

For CTX-3C standard, a six-point calibration curve among the range 37.5-600 ng/mL was done. The limit of detection (LOD) was $1.125 \mu \mathrm{g} / \mathrm{Kg}$ and a limit of quantification (LOQ) was $3.75 \mu \mathrm{g} / \mathrm{Kg}$.

\subsection{UPLC-MS-IT-TOF Conditions}

The UPLC system, from Shimadzu (Kyoto, Japan) consists of two pumps (LC-30AD), autoinjector (SIL-10AC) with refrigerated rack, degasser (DGU-20A), column oven (CTO-10AS) and a system controller (SCL-10Avp). The system is coupled to an IT-TOF-MS system with an electrospray ionization (ESI) interface (Shimadzu, Kyoto, Japan). The nitrogen generator is a Nitrocraft NCLC/MS from Air Liquid (Spain). The separation was performed with an ACQUITY UPLC Phenyl-Hexyl column $(2.1 \times 100 \mathrm{~mm}, 1.7 \mu \mathrm{m}$ particle size, Waters, Spain). Mobile phases A and B were water and acetronitrile:water (95:5), respectively, both acidified with $50 \mathrm{mM}$ formic acid and $2 \mathrm{mM}$ ammonium formate. Chromatographic separation was performed by gradient elution starting with $50 \% \mathrm{~B}$ for $2.5 \mathrm{~min}$, then increasing to $100 \% \mathrm{~B}$ for $4.5 \mathrm{~min}$., this condition was hold for $4.5 \mathrm{~min}$ and reduced afterward to $50 \% \mathrm{~B}$ over $0.1 \mathrm{~min}$. This proportion was maintained $2.4 \mathrm{~min}$. until the next injection to equilibrate the system. The mobile phase flow rate was $0.4 \mathrm{~mL} / \mathrm{min}$, the injection volume was $5 \mu \mathrm{L}$ and the temperature was maintained at $35^{\circ} \mathrm{C}$. The MS method was operated in positive mode with the following ESI source conditions: nebulizing gas flow, $1.5 \mathrm{~L} / \mathrm{min}$, heat block temperature and $\mathrm{CDL}$ temperature, $200{ }^{\circ} \mathrm{C}$ and detector voltage, and $1.65 \mathrm{kV}$. The molecules were analyzed using an ion accumulation time of $10 \mathrm{~ms}$.

\subsection{Statistical Analyses}

The influence of the factors Sampling site (Morocco, Madeira and Azores islands) and organism type in the CTX occurrence was analyzed using Generalized Linear Models (GLZ). The dependent variable was the concentration of CTX in the organisms flesh ( $\mu \mathrm{g}$ CTX-3C equivalents $/ \mathrm{Kg}$ ). Because only the starfish yielded positive results, primarily, we performed an analysis considering only the starfish data, using sampling site as factor. The dataset consists of CTX concentrations found in individual samples from each organism. There is one single data per pooled sample, being the pools constituted by similar numbers of organisms. The data set could be considered as a zero - inflated dataset, with variance larger than the mean. These models are usually handled with Poisson or negative binomial distributions [47]; however, we can use neither of these distribution because our data are continuous. Instead, we used the approach of gamma hurdle models [48], which performs the analysis in two steps: first, the analysis of presence/absence of the toxin (managed with a binomial or negative binomial distribution) and second, on these data showing positive concentrations of CTX, a GLZ with gamma distribution. Besides the 
analysis including sampling site as factor, we performed another analysis considering starfish species as factor.

All the models were performed with R software [49], package stats (), function glm.

\section{Conclusions}

The primary aim of this work was to search for new vectors for CTX in the Portuguese islands and the northwestern coast of Morocco using UPLC-IT-TOF-MS and UPLC-MS/MS techniques. From 22 surveyed species, we detected CTX in two species of starfish: M. glacialis and O. ophidianus. In addition, the quantifiable results were all in Portuguese territory, being São Miguel Island (Azores), the location with greater propensity to find these biotoxin groups. This is an important finding since it is, to the best of our knowledge, the first report of these toxins in echinoderms ever. We detected three analogues, CTX-1B and two unnamed derivatives, in concentrations that ranged from 4.40 to $124.04 \mu \mathrm{g}$ CTX-3C equivalents/Kg fw, especially in the red starfish, O. ophidianus. Since this species has detritivorous feeding habits, this could be the main explanation for considerable difference with regard to accumulated amounts, comparing to the predatory spiny starfish (M. glacialis). Regarding Ciguatera monitoring, starfish present themselves as a good alternative, though more studies should be done in order to understand correlation of CTX uptake between echinoderms and predatory fish, to better evaluate human health risk.

\section{Acknowledgments}

This research was partially funded by the FCT project UID/Multi/04423/2013 and by the projects MARBIOTECH (reference NORTE-07-0124-FEDER-000047) within the SR\&TD Integrated Program MARVALOR - Building research and innovation capacity for improved management and valorization of marine resources, supported by the Programa Operacional Regional do Norte (ON.2-O Novo Norte) and NOVOMAR (reference 0687-NOVOMAR-1-P), supported by the European Regional Development Fund. M.S. also acknowledges FCT for the grant SFRH/BD/73269/2010 and Ana Regueiras, Isadora Diniz, Afonso Prestes and Manuela Maranhão. This research was also partially funded by the FCT-Portugal/CNRST-Morocco Cooperation Convention under the project 1006/13 CNR "Marine emergent toxins in the north east Atlantic (Portugal-Morocco) produced by microalgae and bacteria". I. R. was supported by a fellowship from Subprograma de Formación de Personal Investigador (AGL2012-40185-CO2-01), Spain. The research leading to these results has received funding from the following FEDER cofunded-grants. From CDTI and Technological Funds, supported by Spanish Ministerio de Economía y Competitividad, AGL2012-40185-CO2-01, AGL2014-58210-R, and Consellería de Cultura, Educación e Ordenación Universitaria, GRC2013-016 (Galicia) Spain.

\section{Author Contributions}

M.S. and V.V. conceived the idea, M.S. performed the sampling, sample analyzes and paper writing. I.R. performed the LC-MS/MS and IT-TOF analysis. A.B. collaborated in sample analyzes. A.A. contributed on experimental design. M.H. collaborated in sample collection. V.V. and L.B. contributed in funding, materials and analyses tools. V.V., B.S., A.I.N., and M.K. collaborated in the collections and provided sampling and laboratory facilities. All authors participated in proof reading of the manuscript. 


\section{Conflicts of Interest}

The authors declare no conflict of interest.

\section{References}

1. Alexander, J.; Benford, D.; Boobis, A.; Ceccatelli, S.; Cravedi, J.P.; di Domenico, A.; Doerge, D.; Dogliotti, E.; Edler, L.; Farmer, P.; et al. Efsa panel on contaminants in the food chain; scientific opinion on marine biotoxins in shellfish-Emerging toxins: Ciguatoxin group. EFSA J. 2010, 1627, $1-38$.

2. Murata, M.; Legrand, A.M.; Ishibashi, Y.; Yasumoto, T. Structures of ciguatoxin and its congener. J. Am. Chem. Soc. 1989, 111, 8929-8931.

3. Murata, M.; Legrand, A.M.; Ishibashi, Y.; Fukui, M.; Yasumoto, T. Structures and configurations of ciguatoxin from the Moray eel Gymnothorax javanicus and its likely precursor from the dinoflagellate Gambierdiscus toxicus. J. Am. Chem. Soc. 1990, 112, 4380-4386.

4. Lehane, L.; Lewis, R.J. Ciguatera: Recent advances but the risk remains. Int. J. Food Microbiol. 2000, 61, 91-125.

5. Lewis, R.J.; Sellin, M.; Poli, M.A.; Norton, R.S.; MacLeod, J.K.; Sheil, M.M. Purification and characterization of ciguatoxins from moray eel (Lycodontis javanicus, muraenidae). Toxicon 1991, 29, 1115-1127.

6. Lewis, R.J.; Vernoux, J.P.; Brereton, I.M. Structure of caribbean ciguatoxin isolated from Caranx latus. J. Am. Chem. Soc. 1998, 120, 5914-5920.

7. Pottier, I.; Vernoux, J.P.; Jones, A.; Lewis, R.J. Characterization of multiple caribbean ciguatoxins and congeners in individual specimens of horse-eye jack (Caranx latus) by high performance liquid chromatography/mass spectrometry. Toxicon 2002, 40, 929-939.

8. Vernoux, J.P.; Lewis, R.J. Isolation and characterisation of caribbean ciguatoxins from the horse-eye jack (Caranx latus). Toxicon 1997, 35, 889-900.

9. Satake, M.; Fukui, M.; Legrand, A.M.; Cruchet, P.; Yasumoto, T. Isolation and structures of new ciguatoxin analogs, 2,3-dihydroxyctx3c and 51-hydroxyctx3c, accumulated in tropical reef fish. Tetrahedron Lett. 1998, 39, 1197-1198.

10. Satake, M.; Ishibashi, Y.; Legrand, A.M.; Yasumoto, T. Isolation and structure of ciguatoxin-4a, a new ciguatoxin precursos, from cultures of dinoflagellate Gambierdiscus toxicus and parrotfish Scarus gibbus. Biosci. Biotechnol. Biochem. 1997, 60, 2103-2105.

11. Satake, M.; Murata, M.; Yasumoto, T. Gambierol: A new toxic polyether compound isolated from the marine dinoflagellate Gambierdiscus toxicus. J. Am. Chem. Soc. 1993, 115, 361-362.

12. Satake, M.; Murata, M.; Yasumoto, T. The structure of CTX3C, a ciguatoxin congener isolated from cultured Gambierdsicus toxicus. Tetrahedron Lett. 1993, 34, 1975-1978.

13. Holland, W.C.; Litaker, R.W.; Tomas, C.R.; Kibler, S.R.; Place, A.R.; Davenport, E.D.; Tester, P.A. Differences in the toxicity of six gambierdiscus (dinophyceae) species measured using an in vitro human erythrocyte lysis assay. Toxicon 2013, 65, 15-33.

14. Lu, X.Z.; Deckey, R.; Jiao, G.L.; Ren, H.F.; Li, M. Caribbean maitotoxin elevates $\left[\mathrm{Ca}\left({ }^{2+}\right)\right] \mathrm{i}$ and activates non-selective cation channels in HIT-T15 cells. World J. Diabetes 2013, 4, 70-75. 
15. Pottier, I.; Vernoux, J.P.; Jones, A.; Lewis, R.J., Analysis of toxin profiles in three different fish species causing ciguatera fish poisoning in guadalupe, french west indies. Food Addit. Contam. 2002, 19, 1034-1042.

16. Friedman, M.A.; Fleming, L.E.; Fernandez, M.; Bienfang, P.; Schrank, K.; Dickey, R.; Bottein, M.Y.; Backer, L.; Ayyar, R.; Weisman, R.; et al. Ciguatera fish poisoning: Treatment, prevention and management. Mar. Drugs 2008, 6, 456-479.

17. De Fouw, J.C.; van Egmond, H.P.; Speijers, G.J.A. Ciguatera Fish Poisoning: A Review. Available online: http://www.rivm.nl/bibliotheek/rapporten/388802021.pdf(accessed on 17 December 2010).

18. Bentur, Y.; Spanier, E. Ciguatoxin-like substances in edible fish on the eastern mediterranean. Clin. Toxicol. 2007, 45, 695-700.

19. Hamilton, B.; Hurbungs, M.; Jones, A.; Lewis, R.J. Multiple ciguatoxins present in indian ocean reef fish. Toxicon 2002, 40, 1347-1353.

20. Fda. Fish and Fishery Products Hazards and Controls Guidance. 2011. Available online: http:/www.Fda.Gov/downloads/food/guidancecomplianceregulatoryinformation/guidancedocuments/ seafood/ucm251970.Pdf (accessed on 12 March 2013).

21. Regulation (ec) No 854/2004 of the european parliament and of the council of 29 April 2004 laying down specific rules for the organisation of official controls on products of animal origin intended for human consumption. Oj 1 139, 30.4.2004, pp. 206-320. EURO-LEX; Access to European Law. Available online: http://eur-lex.europa.eu/legal-content/EN/TXT/?uri=CELEX:32007R1246 (accessed on 18 June 2015).

22. Cdc (centers for disease control and prevention), 2009. Cluster of ciguatera fish poisoning-north carolina, 2007. Morbidity and mortality weekly report (mmwr), 58, 283-285. Available from http://www.Cdc.Gov/mmwr/pdf/wk/mm5811.Pdf. Centers of Disease Control and Prevention. Available online: http://www.cdc.gov/ (accessed on 18 June 2015).

23. Carefoot, T.H. Aplysia: Its biology and ecology. Oceanogr. Mar. Biol. Ann. Rev. 1987, 25, 167-284.

24. Bulleri, F.; Benedetti-Cecchi, L.; Cinelli, F. Grazing by the sea urchins Arbacia lixula 1. And Paracentrotus lividus lam. in the northwest mediterranean. J. Exp. Mar. Biol. Ecol. 1999, 241, $81-85$.

25. Lin, S.J.; Hwang, D.F. Possible source of tetrodotoxin in the starfish astropecten scoparius. Toxicon 2001, 39, 573-579.

26. Nicolaidou, A.; Nott, J.A. The role of the marine gastropod Cerithium vulgatum in the biogeochemical cycling of metals. Biogeochem. Cycl. Sediment Ecol. 1999, 59, 137-146.

27. Rodríguez, A.; Hernández, J.C.; Clemente, S.; Coppard, S.E. A new species of diadema (echinodermata:Echinoidea:Diadematidae) from the eastern atlantic ocean and a neotype designation of Diadema antillarum (philippi, 1845). Zootaxa 2013, 3636, 144-170.

28. Ferguson, J.C. Feeding activity in echinaster and its induction with dissolved nutrients. Biol. Bull. 1969, 136, 374-384.

29. Crothers, J.H. Common topshells: An introduction to the biology of Osilinus lineatus with notes on other species in the genus. Field Stud. 2001, 10, 115-160.

30. Navarro, P.G.; García-Sanz, S.; Barrio, J.M.; Tuya, F. Feeding and movement patterns of the sea cucumber Holothuria sanctori. Mar. Biol. 2013, 160, 2957-2966. 
31. Toral-Granda, V.; Lovatelli, A.; Vasconcellos, M. Scientific committee composed of Conand C., Hamel J.F., Mercier A., Purcell S. and Uthicke S. In Proceedings of the International Workshop on the Sustainable Use and Management of Sea Cucumber Fisheries, SPC Beche-deMer Information Bulletin, Puerto Ayora, Galapagos Islands, Ecuador, 19-23 November 2008.

32. Knox, G.A. Hard shores. In The Ecology of Seashores; Kennish, M.J., Ed.; CRC Press: Boca Raton, FL, USA, 2001; pp. 20-86.

33. Buschbaum, C.; Dittmann, S.; Hong, J.S.; Hwang, I.; Strasser, M.; Thiel, M.; Valdivia, N.; Yoon, S.; Reise, K. Mytilid mussels: Global habitat engineers in coastal sediments. Helgol. Mar. Res. 2008, 63, 47-58.

34. Dayrat, B. Review of the current knowledge of the systematics of onchidiidae (mollusca:Gastropoda:Pulmonata) with a checklist of nominal species. Zootaxa 2009, 2068, 1-26.

35. Lemée, R.; Boudouresque, C.F.; Gobert, J.; Malestroit, P.; Mari, X.; Meinesz, A.; Menager, V.; Ruitton, S. Feeding behaviour of paracentrotus lividus in the presence of caulerpa taxifolia introduced in the mediterranean sea. Oceanol. Acta 1995, 19, 245-253.

36. Martinez-Pita, I.; Sanches-Espana, A.; Garcia, F.J. Gonadal growth and reproduction in the sea urchin Sphaerechinus granularis (lamarck 1816) in southern spain. Sci. Mar. 2008, 72, 603-611.

37. Valdes, A. On the publication data, authorship, and type species of Umbraculum and Tylodina gastropoda; opisthobranchia; tylodinoidea. Nautilus 2001, 115, 29-34.

38. Ramírez, R.; Tuya, F.; Haroun, R.J. Spatial patterns in the population structure of the whelk Stramonita haemastoma (linnaeus, 1766) (gastropoda: Muricidae) in the canarian archipelago (eastern atlantic). Sci. Mar. 2009, 73, 431-437.

39. Llewellyn, L.E. Revisiting the association between sea surface temperature and the epidemiology of fish poisoning in the south pacific: Reassessing the link between ciguatera and climate change. Toxicon 2010, 56, 691-697.

40. Chinain, M.; Germain, M.; Deparis, X.; Pauillac, S.; Legrand, A.M. Seasonal abundance and toxicity of the dinoflagellate Gambierdiscus spp. (dinophyceae), the causative agent of ciguatera in tahiti, french polynesia. Mar. Biol. 1999, 135, 259-267.

41. Ashton, M.; Tosteson, T.; Tosteson, C. The effect of elevated temperature on the toxicity of the laboratory cultured dinoflagellate Ostreopsis lenticularis (dinophyceae). J. Trop. Biol. 2003, 51, $1-6$.

42. Matsumoto, T.; Nagashima, Y.; Kusuhara, H.; Sugiyama, Y.; Ishizaki, S.; Shimakura, K.; Shiomi, K. Involvement of carrier-mediated transport system in uptake of tetrodotoxin into liver tissue slices of puffer fish Takifugu rubripes. Toxicon 2007, 50, 173-179.

43. Hirama, M.; Oishi, T.; Uehara, H.; Inoue, M.; Maruyama, M.; Oguri, H.; Satake, M. Total synthesis of ciguatoxin CTX3C. Science 2001, 294, 1904-1907.

44. Inoue, M.; Hirama, M., Evolution of a practical total synthesis of ciguatoxin CTX3C. Account. Chem. Res. 2004, 37, 961-968.

45. Otero, P.; Lopez, S.P.; Alfonso, A.; Vale, C.; Rodríguez, P.; Gouveia, N.N.; Gouveia, N.; Delgado, J.; Vale, P.; Hirama, M.; et al. First toxin profile of ciguateric fish in madeira arquipelago (europe). Anal. Chem. 2010, 82, 6032-6039.

46. Lewis, R.J.; Yang, A.; Jones, A. Rapid extraction combined with lc-tandem mass spectrometry (crem-lc/ms/ms) for the determination of ciguatoxins in ciguateric fish flesh. Toxicon 2009, 54, 62-66. 
47. Zuur, A.F.; Ieno, E.N.; Walker, N.J.; Saveliev, A.A.; Smith, G.M. Mixed Effects Models and Extensions in Ecology with R; Springer Science: New York, NY, USA, 2009.

48. Frees, E.W. Regression Modeling with Actuarial and Financial Applications; Cambridge University Press: New York, NY, USA, 2011.

49. R Core Team. A Language and Environment for Statistical Computing. R Foundation for Statistical Computing. 2014. Available online: http://www.R-project.org/ (accessed on 2 June 2015).

(C) 2015 by the authors; licensee MDPI, Basel, Switzerland. This article is an open access article distributed under the terms and conditions of the Creative Commons Attribution license (http://creativecommons.org/licenses/by/4.0/). 